\title{
Linear Thanatin Is an Effective Antimicrobial Peptide against Colistin-Resistant Escherichia coli in Vitro
}

\author{
Quan Zhou1, Huimin Fan', Peifeng Lu', Yuyan Zhou', Wei Li', Jianhua Liu' \\ ${ }^{1}$ Guangdong Hinabiotech Co., Ltd., Guangzhou, China \\ ${ }^{2}$ National Reference Laboratory of Veterinary Drug Residues, College of Veterinary Medicine, South China Agricultural \\ University, Guangzhou, China \\ Email: liwei@sjtu.edu.cn,jhliu@scau.edu.cn
}

How to cite this paper: Quan Zhou, Huimin Fan, Peifeng Lu, Yuyan Zhou, Wei Li, Jianhua Liu (2018) Linear Thanatin Is an Effective Antimicrobial Peptide against Colistin-Resistant Escherichia coli in Vitro. Advances in Microbiology, 8, 589-599. https://doi.org/10.4236/aim.2018.87039

Received: June 11, 2018

Accepted: July 27, 2018

Published: July 30, 2018

Copyright $\odot 2018$ by authors and Scientific Research Publishing Inc. This work is licensed under the Creative Commons Attribution International License (CC BY 4.0).

http://creativecommons.org/licenses/by/4.0/

\begin{abstract}
Colistin has been regarded as the last line antibiotic for treatment of infections caused by multidrug resistant gram-negative bacteria. Therefore, the increasing emergence of colistin resistance among gram-negative bacteria represents a serious problem. The objective of this study was to characterize the effectiveness of the chemically synthesized thanatin in linear form against colistin-resistant E. coli isolated from a pig farm in China. Agar diffusion assay and broth microdilution test were employed to analyze the susceptibility of colistin-sensitive E. coli (ATCC25922) and colistin-resistant E. coli (SHP45) to linear thanatin (L-thanatin). Combinatory effect of linear thanatin and colistin against $E$. coli was also determined by fractional inhibition concentration index (FICI) analysis. The results showed that L-thanatin at a concentration of $1 \mathrm{mg} / \mathrm{ml}$ produced larger inhibition zone on agar against ATCC25922 than SHP45. In the quantitative microdilution test, L-thanatin had the same MIC of $3.2 \mu \mathrm{g} / \mathrm{ml}$ for ATCC25922 and SHP45. Based on the FICI analysis, additive effect was obtained with $1.56 \mu \mathrm{g} / \mathrm{ml}$ of L-thanatin and $0.125 \mu \mathrm{g} / \mathrm{ml}$ of colistin for ATCC25922; but with $1.56 \mu \mathrm{g} / \mathrm{ml}$ of L-thanatin and $0.25 \mu \mathrm{g} / \mathrm{ml}$ of colistin or with $2 \mu \mathrm{g} / \mathrm{ml}$ of colistin and $0.39 \mu \mathrm{g} / \mathrm{ml}$ of L-thanatin for SHP45. These data proved that L-thanatin is an effective antimicrobial peptide against colistin-resistant E. coli.
\end{abstract}

\section{Keywords}

E. coli, Colistin Resistance, Linear Thanatin, Minimum Inhibition

Concentration, Fractional Inhibition Concentration Index 


\section{Introduction}

Infections caused by antibiotic-resistant pathogens, particularly gram-negative bacteria (GNB) have posed significant challenges for public health [1]. The emergence and spread of multidrug-resistant (MDR) strains of Enterobacteriaceae such as E. coli, salmonella, etc. have exposed limited options for treating infections caused by these microorganisms [2]. The polymyxins including Polymyxin B and colistin (polymyxin E) have been used as Gram-negative therapeutics since their discovery in late 1940s [3] [4]. Today, colistin has become the last line drug for MDR Gram-negative bacteria infections [5].

Colistin has been also extensively applied orally since the 1960s in food animals and particularly in swine for the control of Enterobacteriaceae infections [6]. However, after decades of colistin use in swine, scientists discovered a significant resistance rate of Enterobacteriaceae to colistin in pigs [6] [7] [8] [9]. The most common mechanism of colistin-resistance in E. coli and Salmonella involves up-regulation of LPS-modifying genes encoded on chromosomes [10] Researchers have also identified stable plasmid mediated mcr-1 gene, which encodes phosphoethanolamine transferase, conferring resistance to colistin in $E$. coli [11] [12]. The finding of this horizontal transferrable mechanism has raised the alert level of colistin resistance that spreads in animal production. Moreover, it has also been confirmed that colistin resistant $E$. coli strain can transfer between pigs and humans through direct contact [13]. This has raised serious concerns about the possible loss of colistin effectiveness in treating MDR-GNB in humans. Hence, there is an urgent need to control the spread of colistin resistant E. coli strains as well as develop new effective pharmaceuticals to treat infections caused by them.

Thanatin is a cysteine-containing antimicrobial peptide that was isolated from the hemipteran insect Podisus maculiventris [14]. It has a broad spectrum of activity against Gram-negative bacteria, Gram-positive bacteria and fungi [14]. Thanatin consists of 21 amino acids, the two cysteine residues on position 11 and position 18 form a disulfide bridge which maintains the core anti-parallel $\beta$-sheet structure in solution [15]. Thanatin has drawn considerable interest for its satisfactory activity against MDR gram-negative bacteria [16] [17] [18]. Furthermore, it is comparatively safe for the low hemolytic and cytotoxic activity [19]. Intriguingly, the linear thanatin analogue (L-thanatin) without disulfide bond has been shown to have similar activity against extended-spectrum- $\beta$-lactamase (ESBL)-producing Escherichia coli [20]. This will further reduce the cost of thanatin peptide synthesis. In this study, the antimicrobial activity of L-thanatin was evaluated in vitro against the colistin-resistant $E$. coli strain-SHP45 isolated from an intensive pig farm in China.

\section{Materials and Methods}

\subsection{Chemicals}

Colistin sulfate was purchased from Sigma-Aldrich (St. Louis, MO, USA). Dif- 
$\mathrm{co}^{\mathrm{TM}}$ Mueller Hinton Broth (MHB) was ordered from BD (Franklin Lakes, NJ, USA). All other chemicals and reagents used were of analytical grade.

\subsection{Organisms}

The colistin-resistant E. coli strain SHP45 was preserved in National Risk Assessment Laboratory for Antimicrobial Resistance of Microorganisms in Animals, South China Agricultural University, Guangzhou, China. E. coli ATCC 25,922 obtained from the Chinese National Center for Surveillance of Antimicrobial Resistance (Beijing, China) was used as a reference strain.

\subsection{Peptide Synthesis}

L-thanatin (GSKKPVPIIYCNRRTGKCQRM) and Stomoxyn [21] (RGFRKHFNKLVKKVKHTISETAHVAKDTAVIAGSGAAVVAATG) was synthesized by GL Biochem (Shanghai) Ltd. (Shanghai, China) using classic Fmoc methodology. The synthetic peptide was purified to over $90 \%$ chromatographic homogeneity by reverse-phase high-performance liquid chromatography (RP-HPLC). The purified peptide was then analyzed using a MALDI-TOF mass spectrometer. The molecular masses of the detected L-thanatin and stomoxyn were 2435.95 and 4474.19 , which were in good agreement with the calculated masses (2435.97 Da and 4479.22).

\subsection{Agar Diffusion Assay}

Fresh E. coli colonies were inoculated into $5 \mathrm{ml}$ sterile $\mathrm{MHB}$ and grow at $37^{\circ} \mathrm{C}$ for $16 \mathrm{~h}$. The bacteria cells were collected by centrifugation and resuspended with saline, the cell density was adjusted to approximately $2.5 \times 10^{9} \mathrm{CFU} / \mathrm{ml} .50$ $\mu \mathrm{l}$ of the suspension was then mixed with $50 \mathrm{ml}$ of autoclaved MHA maintained at $50^{\circ} \mathrm{C} .10 \mathrm{ml}$ of the resulting mixture was poured into each $10-\mathrm{cm}$-diameter sterile petri dishes. The dishes were left ajar in a super-clean bench for $1 \mathrm{~h}$ until the agar solidified. Wells of $2.7 \mathrm{~mm}$ diameter were made with a sterile puncher. $5 \mathrm{ul}$ of colistin, stomoxyn and thanatin solution at the same concentration (1 $\mathrm{mg} / \mathrm{ml}$ in water) were added to separate well. Sterile deionized water was used as the negative control, stomoxyn was used as a positive control. The plates were incubated at $37^{\circ} \mathrm{C}$ for $16 \mathrm{~h}$ and the clear zones of inhibition were observed and the diameters of the zones were measured. Data were reported as mean and standard deviation (SD).

\subsection{Bacterial Susceptibility Assay}

The minimum inhibitory concentration (MIC) and the bactericidal concentration $(\mathrm{MBC})$ of colistin and L-thanatin were determined by microdilution method in accordance with the Clinical and Laboratory Standards Institute (CLSI) guideline M31-A3 (National Committee for Clinical Laboratory Standards (NCCLS): 2004, Performance standards for antimicrobial disk and dilution susceptibility tests for bacteria isolated from animals, informational supplement M31-S1. NCCLS, Wayne, PA). Briefly, Mueller-Hinton (MH) broth $(100 \mu \mathrm{l})$ 
containing E. coli $\left(5 \times 10^{5} \mathrm{CFU} / \mathrm{ml}\right)$ was added to $100 \mu \mathrm{l}$ of the culture medium containing colistin ( 0.25 to $128 \mu \mathrm{g} / \mathrm{ml}$ in serial 2 -fold dilutions) thanatin ( 0.39 to $100 \mu \mathrm{g} / \mathrm{ml}$ in serial 2-fold dilutions). The plates were incubated at $37^{\circ} \mathrm{C}$ for $20 \mathrm{~h}$ in an incubator. The MBC was reported as the lowest concentration producing a 99.9\% reduction in bacterial viable count in the sub-cultured well contents, relative to the initial inoculum. Concisely, immediately after inoculation, $0.1 \mathrm{ml}$ of the positive control well were subcultured onto Mueller-Hinton agar (MHA) plates and incubated at $37^{\circ} \mathrm{C}$ for $16 \mathrm{~h}$. Likewise, immediately after MIC testing, $0.1 \mathrm{ml}$ of bacterial cultures that showed negative bacteria growth were spread evenly on MHA plates and were grown under the same condition as the positive control. The colonies on each plate were enumerated.

To monitor the bacterial growth responding to the treatments of antibiotic substances, equal volume of $2 \times$ L-thanatin solutions were added to separate wells bacteria cultures $(\mathrm{OD} 600=0.04)$ to achieve different final concentrations $(0.25,0.5,1.0,1.5 \mu \mathrm{g} / \mathrm{ml})$ with the addition of MHB as a control. The optical densities at $600 \mathrm{~nm}$ for the colistin-resistant strain E. coli SHP45 and the reference strain E. coli ATCC 25,922 were recorded using a Biotek Synergy 2 microplate reader at $37^{\circ} \mathrm{C}$ at 2 -h intervals for $24 \mathrm{~h}$. The growth curves were drawn by plotting optical densities on the $\mathrm{Y}$-axis and the growth times on the $\mathrm{X}$-axis. Duplicate experiments were done and for the construction of growth curves.

\subsection{Synergy Testing (FIC Index Analysis)}

Chequerboard assay was employed to study the interaction between L-thanatin and colistin against E. coli according to the protocol published by others [21]. Serial twofold dilutions of the antimicrobials were combined in each well of a 96-well microtitre plate so that each row (and column) contained a fixed concentration of one agent $(50 \mu \mathrm{l})$ and increasing concentrations of the other agent $(50 \mu \mathrm{l})$. Mueller-Hinton $(\mathrm{MH})$ broth $(100 \mu \mathrm{l})$ containing E. coli $\left(5 \times 10^{5}\right.$ $\mathrm{CFU} / \mathrm{ml}$ ) was then added to each well. The MICs for each combination were determined as described above.

Fractional inhibitory concentration (FIC) was calculated based on the MIC data. The FIC of an individual antimicrobial compound is defined as the ratio of the concentration of the antimicrobial in the inhibitory concentration with a second compound to the concentration of the antimicrobial by itself [16]. The formula is as follows: FIC $_{\mathrm{A}}=$ MIC of A with B/MIC of A. The FIC index for each combination was then calculated as the sum of $\mathrm{FIC}_{\mathrm{A}}$ and $\mathrm{FIC}_{\mathrm{B}}$. The interaction was defined as synergistic if the FIC index was $\leq 0.5$, additive if the FIC index was $>0.5$ and $\leq 1.0$, indifferent if the FIC index was $>1.0$ and $\leq 2.0$, and antagonistic if the FIC index was $>2.0$ [22].

\section{Results}

\subsection{Comparison of the Susceptibility of Reference Strain and Colistin-Resistant Strain by Agar Diffusion Assay}

Clear zones of inhibition were observed for Stomoxyn, colistin and thanatin 
spotted wells except the negative control well (Figure 1). The zone diameter generated by thanatin was comparable to that produced by colistin. But upon close inspection, the transparency of inhibition zone produced by thanatin was lower than that generated by colistin. In addition, both colistin and thanatin produced larger inhibition zones against ATCC25922 than SHP45 (Table 1).

\subsection{Comparison of the Susceptibility of Reference Strain and Colistin-Resistant Strain by Microdilution Assay}

As shown in Table 2, both E. coli strains ATCC 25922 and SHP45 had identical MIC and MBC values towards colistin. However, the colistin MIC/MBC values between the two strains were significantly different. The MIC/MBC value of SHP45 to colistin $(4 \mu \mathrm{g} / \mathrm{ml})$ was 3 -fold higher than that of ATCC 25922 (1 $\mu \mathrm{g} / \mathrm{ml})$. L-thanatin exerted potent antibacterial effects against both colistin-susceptible E. coli ATCC25922 and colistin-rsistant E. coli SHP45. The MIC values for these two strains were the same $(3.12 \mu \mathrm{g} / \mathrm{ml})$. Notably, the MBC value for ATCC 25922 was same as its MIC value; but the MBC value for SHP 45 was $6.25 \mathrm{ug} / \mathrm{ml}$, which was 1 -fold higher than its MIC.

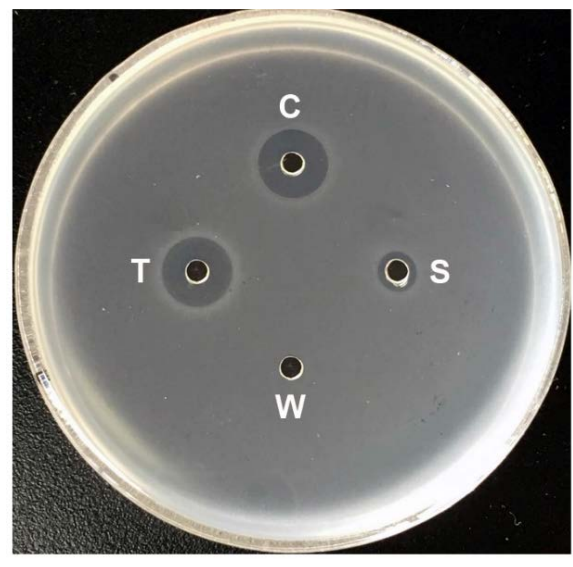

(a)

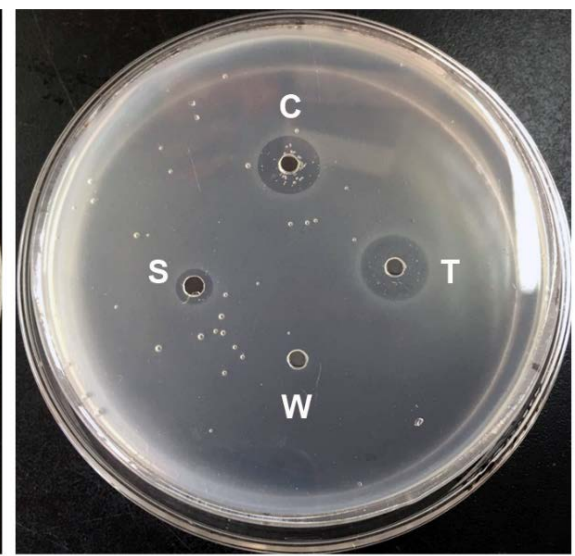

(b)

Figure 1. Characterization of antibacterial activities of colistin and thanatin against E. coli by agar well diffusion assay. E. coli culture was mixed with MHA to a final density of $2.3 \times 10^{6} \mathrm{cfu} / \mathrm{ml}$. Punched wells were filled with $5 \mu \mathrm{l}$ of colistin (c) stomoxyn (S), thanatin (T) solutions $(1 \mathrm{mg} / \mathrm{ml})$ or deionized water $(\mathrm{W})$ respectively. Pictures were taken after incubating the plates for 16 hours at $37^{\circ} \mathrm{C}$; (a) E. coli strain ATCC25922; (b) E. coli strain SHP45. Representative data from one of the three independent experiments are shown.

Table 1. The diameters of inhibition zones produced by colistin and L-thanatin in muller-Hinton agar*.

\begin{tabular}{ccc}
\hline & \multicolumn{2}{c}{ Diameter $(\mathrm{mm})$} \\
\hline Strain & Colistin & L-thanatin \\
\hline E. coli ATCC 25922 & $13.80 \pm 0.34$ & $14.21 \pm 0.48$ \\
E. coli SHP 45 & $11.31 \pm 0.27$ & $11.80 \pm 0.53$ \\
\hline
\end{tabular}

*: Data were obtained from three repetitive experiments. 
On evaluating the effect of different concentrations of thanatin on the growth of $E$. coli, it was found that $1 \mu \mathrm{g} / \mathrm{ml} \mathrm{L-thanatin} \mathrm{significantly} \mathrm{inhibited} \mathrm{the} \mathrm{growth}$ of both ATCC25922 and SHP45 strains. Total growth inhibition of both strains was achieved at dosages of $1.5 \mathrm{ug} / \mathrm{ml}$ (Figure 2).

Table 2. MICs and MBCs of colistin and L-thanatin in Mueller-Hinton broth culture*.

\begin{tabular}{ccccc}
\hline & \multicolumn{2}{c}{ MIC $(\mu \mathrm{g} / \mathrm{ml})$} & \multicolumn{2}{c}{$\mathrm{MBC}(\mu \mathrm{g} / \mathrm{ml}))$} \\
\hline Strain & Colistin & L-thanatin & Colistin & L-thanatin \\
\hline E. coli ATCC 25922 & 1 & 3.12 & 1 & 3.12 \\
E. coli SHP 45 & 4 & 3.12 & 4 & 6.25 \\
\hline
\end{tabular}

*: all values were obtained from three repetitive experiments.

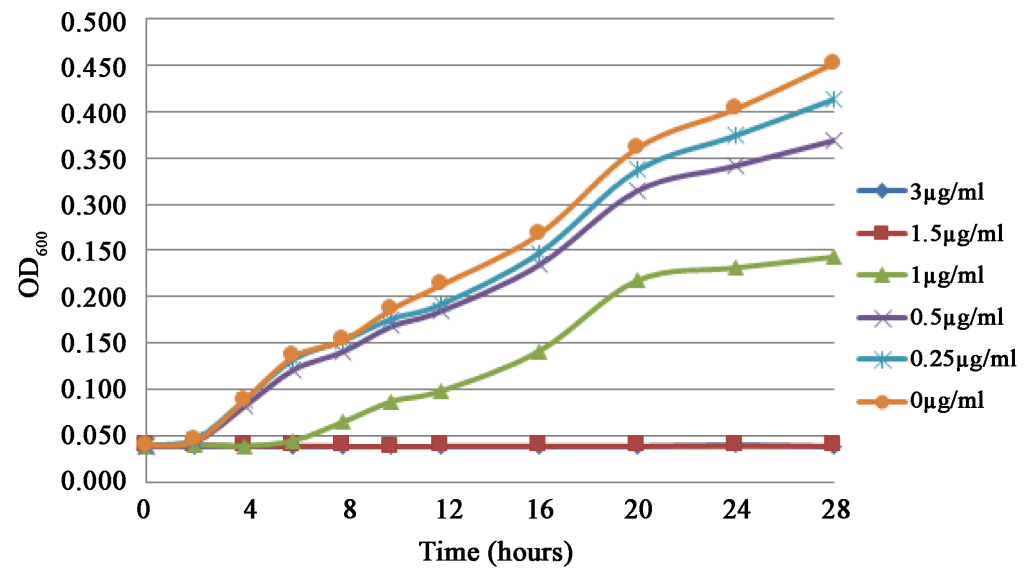

(a)

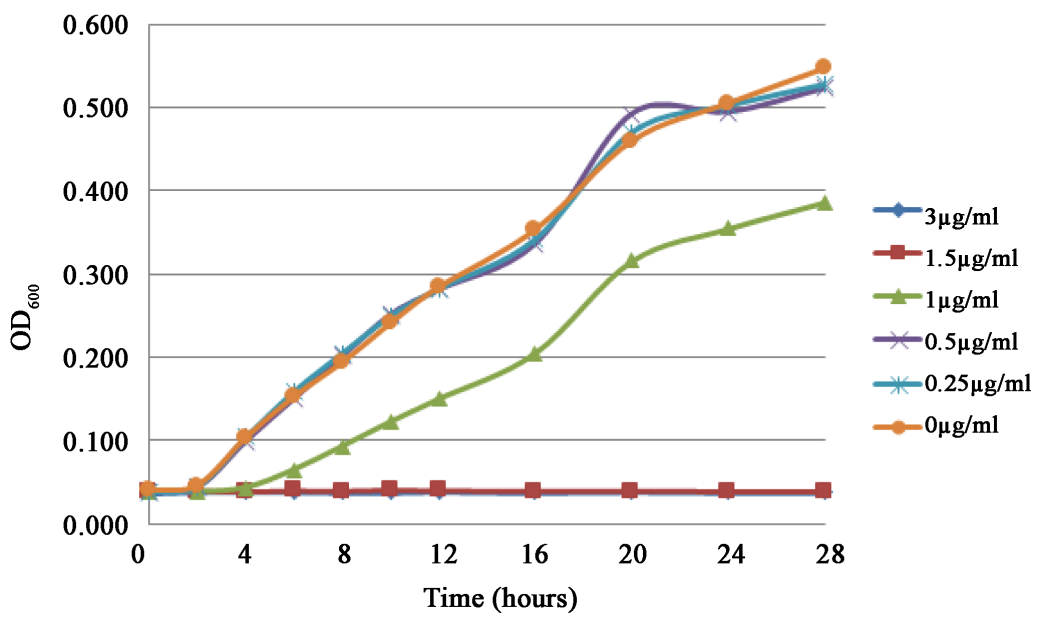

(b)

Figure 2. Growth inhibition of $E$. coli induced by thanatin treatment. E. coli culture was adjusted to a density of $\mathrm{OD}_{600}=0.04$, and incubated with different concentrations of thanatin $(0,0.25,0.5,1,1.5,3.0 \mu \mathrm{g} / \mathrm{ml})$. Bacterial density was measure at $\mathrm{OD}_{600}$ in 2-hour intervals. Growth curve was constructed by plotting $\mathrm{OD}_{600}$ on the $\mathrm{Y}$-axis and the growth times on the X-axis. A. E. coli strain ATCC25922; B. E. coli strain SHP45. Representative data from one of the two independent experiments are shown. 


\subsection{Combinatorial Effect on $E$. coli}

To test the interaction of L-thanatin and colistin against $E$. coli, the checkerboard assay was conducted to test the effect of different combinations of the above two antimicrobials on the growth of the colistin-susceptible ATCC25922 reference strain and the colistin-resistant SHP45 strain. As a result, different modes of interaction (additive and indifferent) were observed. However, no synergism or antagonism was obtained with all combinations. The combinations that had additive effect were summarized in Table 3 . The best calculated FICI for ATCC 25922 was 0.625 obtained with $1.56 \mu \mathrm{g} / \mathrm{ml}$ of thanatin and $0.125 \mu \mathrm{g} / \mathrm{ml}$ of colistin. The best calculated FICI for SHP 45 was same as ATCC25922, but was obtained with $1.56 \mu \mathrm{g} / \mathrm{ml}$ of thanatin and $0.25 \mu \mathrm{g} / \mathrm{ml}$ of colistin or with $2 \mu \mathrm{g} / \mathrm{ml}$ of colistin and $0.39 \mu \mathrm{g} / \mathrm{ml}$ of thanatin.

\section{Discussion}

The evolution of multidrug-resistant bacteria can be attributed to the overuse and misuse of antibiotics, not only in human medicine, but also in animal husbandry and veterinary medicine. The emergence of antibiotic-resistant bacteria that are difficult or impossible to treat is causing global health crisis [23]. Resistance trends in gram-negative bacteria are particularly alarming due to limited antibiotic options to treat infections incurred by these microorganisms [24]. Therefore, new antimicrobial agents that are both safe and effective are urgently needed.

Colistin is one of the most effective peptide antibiotics against multidrug-resistant (MDR) gram-negative bacteria [25]. It has been used as a feed antibiotic additive for animals in China since 1986. With the discovery that plasmid encoded mcr-1 gene could mediate transferable colistin-resistance in E. coli [11], China has banned the use of colistin for growth promoting purposes. The demand for finding substitutes for colistin to deal with gram-negative bacteria, especially colistin-resistant E. coli, has prompted us to evaluate the efficacy of thanatin against colistin-susceptible as well as colistin-resistant $E$. coli.

In this study, we found that the synthesized L-thanatin has the same minimum inhibition concentration $(3.12 \mu \mathrm{g} / \mathrm{ml})$ against the colistin-sensitive ATCC25922 strain and the colistin-resistant SHP45 strain. At low bacteria densities $(\mathrm{OD} 600 \leq 0.04), 1.5 \mu \mathrm{g} / \mathrm{ml}$ or higher concentrations of L-thanatin was enough to completely inhibit the growth of ATCC25922 and SHP45 strains in

Table 3. MIC values of thanatin, colistin alone and in combinations, and FIC index values of combinations against E. coli.

\begin{tabular}{ccccc}
\hline Strain & MIC $^{\mathrm{a}}$ & \multicolumn{2}{c}{ MIC $\left(\mathrm{FICI}^{\mathrm{b}}\right)$ in mixture } \\
\hline & L-Thanatin & Colistin & L-Thanatin + Colistin & Colistin + L-Thanatin \\
\hline ATCC25922 & 3.12 & 1 & $1.56 / 0.125(0.625)$ & $0.50 / 0.78(0.75)$ \\
SHP45 & 3.12 & 4 & $1.56 / 0.5(0.625)$ & $2.00 / 0.39(0.625)$ \\
\hline
\end{tabular}

a: Concentrations are given in $\mu \mathrm{g} / \mathrm{ml}$. b: FICI stands for fractional inhibitory concentration index. 
Mueller-Hinton broth culture. Previously, Wu et al. (2011) demonstrated that the antimicrobial activity of S-thanatin (an analogue of thanatin) is independent on the multi-drug resistant spectrum of gram-negative bacteria. Our results have added more evidence to their findings because colistin-resistant strains were not included in their study.

Combination of antimicrobials offers a potential for increasing antimicrobial treatment efficacy and for reducing resistance evolution [26]. Synergy between colistin and other antibiotics have been reported [27] [28]. We have tested the combinatorial effect of L-thanatin and colistin against colistin-resistant E. coli but only found concentration-dependent additive effect at certain combinations. This may be attributed to the fact that both colistin and thanatin act on E. coli though similar mechanisms of binding to lipo polysaccharide (LPS) and altering the integrity of cell membrane [17] [29] [30].

\section{Conclusion}

Colistin has been one of the most potent peptide antibiotics against gram-negative bacteria. However, the emergence of colistin-resistant E. coli has posed growing threat to human and animal health. Previous studies have shown that thanatin derived from insect is an effective peptide against $E$. coli. Nevertheless, the isolation of thanatin from its natural source or production by genetic engineering in large quantity has not been very successful. Linear thanatin has comparable antibacterial activity to its native form and can be manufactured by chemical synthesis. Our results showed that thanatin in linear form was effective against colistin-susceptible and colistin-resistant $E$. coli in vitro. It can be a potential drug candidate for treating infections caused by colistin-resistant $E$. coli. In vivo studies remain to be done to characterize its pharmaceutical effects on $E$. coli infection in animal models.

\section{Ethical Approval}

Approved.

\section{Competing Interests}

The authors declare that they have no competing interests.

\section{References}

[1] Thabit, A.K., Crandon, J.L. and Nicolau, D.P. (2015) Antimicrobial Resistance: Impact on Clinical and Economic Outcomes and the Need for New Antimicrobials. Expert Opinion on Pharmacotherapy, 16, 159-177. https://doi.org/10.1517/14656566.2015.993381

[2] Moxon, C.A. and Paulus, S. (2016) Beta-Lactamases in Enterobacteriaceae Infections in Children. Journal of Infection, 72, S41-S49. https://doi.org/10.1016/j.jinf.2016.04.021

[3] Ainsworth, G.C., Brown, A.M. and Brownlee, G. (1947) Aerosporin, an Antibiotic Produced by Bacillus aerosporus Greer. Nature, 159, 263. 
[4] Schoenbach, E.B. and Bryer, M.J. (1948) The Clinical Use of Polymyxin. Bulletin of Johns Hopkins Hospital, 82, 637-639.

[5] Brown, P. and Dawson, M.J. (2017) Development of New Polymyxin Derivatives for Multi-Drug Resistant Gram-Negative Infections. The Journal of Antibiotics (Tokyo), 70, 386-394. https://doi.org/10.1038/ja.2016.146

[6] Rhouma, M., Beaudry, F., Thériault, W. and Letellier, A. (2016) Colistin in Pig Production: Chemistry, Mechanism of Antibacterial Action, Microbial Resistance Emergence, and One Health Perspectives. Frontiers in Microbiology, 7, 1789.

[7] Harada, K., Asai, T., Kojima, A., Oda, C., Ishihara, K. and Takahashi, T. (2005) Antimicrobial Susceptibility of Pathogenic Escherichia coli Isolated from Sickcattle and Pigs in Japan. Journal of Veterinary Medical Science, 67, 999-1003.

[8] Enne, V.I., Cassar, C., Sprigings, K., Woodward, M.J. and Bennett, P.M. (2008) A High Prevalence of Antimicrobial Resistant Escherichia coli Isolated from Pigs and a Low Prevalence of Antimicrobial Resistant E. coli from Cattle and Sheep in Great Britain at Slaughter. FEMS Microbiology Letters, 278, 193-199.

https://doi.org/10.1111/j.1574-6968.2007.00991.x

[9] Lu, L., Dai, L., Wang, Y., Wu, C., Chen, X., Li, L., Qi, Y., Xia, L. and Shen, J. (2010) Characterization of Antimicrobial Resistance and Integrons among Escherichia coli Isolated from Animal Farms in Eastern China. Acta Tropica, 113, 20-25. https://doi.org/10.1016/j.actatropica.2009.08.028

[10] Olaitan, A.O., Morand, S. and Rolain, J.M. (2014) Mechanisms of Polymyxin Resistance: Acquired and Intrinsic Resistance in Bacteria. Frontiers in Microbiology, 5, 643.

[11] Liu, Y.Y., Wang, Y., Walsh, T.R., Yi, L.X., Zhang, R., Spencer, J., Doi, Y., Tian, G., Dong, B., Huang, X., Yu, L.F., Gu, D., Ren, H., Chen, X., Lv, L., He, D., Zhou, H., Liang, Z., Liu, J.H. and Shen, J. (2016) Emergence of Plasmid-Mediated Colistin Resistance Mechanism MCR-1 in Animals and Human Beings in China: A Microbiological and Molecular Biological Study. The Lancet Infectious Diseases, 16, 161-168. https://doi.org/10.1016/S1473-3099(15)00424-7

[12] Olaitan, A.O., Thongmalayvong, B., Akkhavong, K., Somphavong, S., Paboriboune, P., Khounsy, S., Morand, S. and Rolain, J.M. (2015) Clonal Transmission of a Colistin-Resistant Escherichia coli from a Domesticated Pig to a Human in Laos. Journal of Antimicrobial Chemotherapy, 70, 3402-3404.

[13] Olaitan, A.O., Chabou, S., Okdah, L., Morand, S. and Rolain, J.M. (2016) Dissemination of the MCR-1 Colistin Resistance Gene. The Lancet Infectious Diseases, 16, 147. https://doi.org/10.1016/S1473-3099(15)00540-X

[14] Fehlbaum, P., Bulet, P., Chemysh, S., Briand, J.P., Rousse, J.P., Letellier, L., et al. (1996) Structure Activity Analysis of Thanatin, a 21-Residue Inducible Insect Defense Peptide with Sequence Homology to Frog Skin Antimicrobial Peptides. Proceedings of the National Academy of Sciences, 93, 1221-1225.

https://doi.org/10.1073/pnas.93.3.1221

[15] Mandard, N., Sodano, P., Labbe, H., Bonmatin, J.M., Bulet, P., Hetru, C., Ptak, M. and Vovelle, F. (1998) Solution Structure of Thanatin, a Potent Bactericidal and Fungicidal Insect Peptide, Determined from Proton Two-Dimensional Nuclear Magnetic Resonance Data. European Journal of Biochemistry, 256, 404-410. https://doi.org/10.1046/j.1432-1327.1998.2560404.x

[16] Pagès, J.M., Dimarcq, J.L., Quenin, S. and Hetru, C. (2003) Thanatin Activity on Multidrug Resistant Clinical Isolates of Enterobacter aerogenes and Klebsiella pneumoniae. International Journal of Antimicrobial Agents, 22, 265-269. 
https://doi.org/10.1016/S0924-8579(03)00201-2

[17] Wu, G., Fan, X., Li, L., Wang, H., Ding, J., Hongbin, W., Zhao, R., Gou, L., Shen, Z. and $\mathrm{Xi}, \mathrm{T}$. (2010) Interaction of Antimicrobial Peptide s-Thanatin with Lipopolysaccharide in Vitro and in an Experimental Mouse Model of Septic Shock Caused by a Multidrug-Resistant Clinical Isolate of Escherichia coli. International Journal of Antimicrobial Agents, 35, 250-254.

https://doi.org/10.1016/j.ijantimicag.2009.11.009

[18] Wu, G., Li, X., Fan, X., Wu, H., Wang, S., Shen, Z. and Xi, T. (2011) The Activity of Antimicrobial Peptide S-Thanatin Is Independent on Multidrug-Resistant Spectrum of Bacteria. Peptides, 32, 1139-1145. https://doi.org/10.1016/j.peptides.2011.03.019

[19] Edwards, I.A., Elliott, A.G., Kavanagh, A.M., Zuegg, J., Blaskovich, M.A. and Cooper, M.A. (2016) Contribution of Amphipathicity and Hydrophobicity to the Antimicrobial Activity and Cytotoxicity of $\beta$-Hairpin Peptides. ACS Infectious Diseases, 2, 442-450. https://doi.org/10.1021/acsinfecdis.6b00045

[20] Ma, B., Niu, C., Zhou, Y., Xue, X., Meng, J., Luo, X. and Hou, Z. (2016) The Disulfide Bond of the Peptide Thanatin Is Dispensible for Its Antimicrobial Activity in Vivo and in Vitro. Antimicrobial Agents Chemotherapy, 60, 4283-4289. https://doi.org/10.1128/AAC.00041-16

[21] Boulanger, N., Munks, R.J., Hamilton, J.V., Vovelle, F., Brun, R., Lehane, M.J. and Bulet, P. (2002) Epithelial Innate Immunity. A Novel Antimicrobial Peptide with Antiparasitic Activity in the Blood-Sucking Insect Stomoxys calcitrans. Journal of Biological Chemistry, 277, 49921-49926. https://doi.org/10.1074/jbc.M206296200

[22] Del Valle, P., Garcia-Armesto, M.R., De Arriaga, D., Alez-Donquiles, C.G., Rodriguez-Fernandez, P. and Rua, J. (2016) Antimicrobial Activity of Kaempferol and Resveratrol in Binary Combinations with Parabens or Propyl Gallate against Enterococcus faecalis. Food Control, 61, 213-220.

https://doi.org/10.1016/j.foodcont.2015.10.001

[23] Lee, Y.S., Kang, O.H., Choi, J.G., Oh, Y.C., Chae, H.S., Kim, J.H., Park, H., Sohn, D.H., Wang, Z.T. and Kwon, D.Y. (2008) Synergistic Effects of the Combination of Galangin with Gentamicin against Methicillin-Resistant Staphylococcus aureus. The Journal of Microbiology, 46, 283-288. https://doi.org/10.1007/s12275-008-0012-7

[24] Blair, J.M., Webber, M.A., Baylay, A.J., Ogbolu, D.O. and Piddock, L.J. (2015) Molecular Mechanisms of Antibiotic Resistance. Nature Reviews Microbiology, 13, 42-51. https://doi.org/10.1038/nrmicro3380

[25] Alonso, C.A., Zarazaga, M., Ben Sallem, R., Jouini, A., Ben Slama, K. and Torres, C. (2017) Antibiotic Resistance in Escherichia coli in Husbandry Animals: The African Perspective. Letters in Applied Microbiology, 64, 318-334. https://doi.org/10.1111/lam.12724

[26] Zavascki, A.P., Goldani, L.Z., Li, J. and Nation, R.L. (2007) Polymyxin B for the Treatment of Multidrug-Resistant Pathogens: A Critical Review. Journal of Antimicrobial Chemotherapy, 60, 1206-1215. https://doi.org/10.1093/jac/dkm357

[27] Bollenbach, T. (2015) Antimicrobial Interactions: Mechanisms and Implications for Drug Discovery and Resistance Evolution. Current Opinion in Microbiology, 27, 1-9. https://doi.org/10.1016/j.mib.2015.05.008

[28] Mohammadi, M., Khayat, H., Sayehmiri, K., Soroush, S., Sayehmiri, F., Delfani, S., Bogdanovic, L. and Taherikalani, M. (2017) Synergistic Effect of Colistin and Rifampin against Multidrug Resistant Acinetobacter baumannii: A Systematic Review and Meta-Analysis. The Open Microbiology Journal, 11, 63-71. https://doi.org/10.2174/1874285801711010063 
[29] Lenhard, J.R., Nation, R.L. and Tsuji, B.T. (2016) Synergistic Combinations of Polymyxins. International Journal of Antimicrobial Agents, 48, 607-613.

https://doi.org/10.1016/j.ijantimicag.2016.09.014

[30] Velkov, T., Thompson, P.E., Nation, R.L. and Li, J. (2010) Structure-Activity Relationships of Polymyxin Antibiotics. Journal of Medicinal Chemistry, 53, 1898-1916. https://doi.org/10.1021/jm900999h 